\title{
High dose interferon treatment in chronic hepatitis C
}

S Ino

Institute of Medical Science,

School of Medicine, St Marianna

University,

Japan

$S$ Iino

Correspondence to:

Dr S Iino,

Institute of Medical Science,

School of Medicine

St Marianna University,

2-16-11 Sugao,

Miyamae-ku,

Kawasaki City, Japan.

\begin{abstract}
One hundred and twenty six patients were enrolled in a study to assess the effect of different interferon alfa-2b treatment regimens on the rate of increase in alanine aminotransferase (ALT) activities after treatment. Results indicated that a high daily dosage of interferon (10 million units (MU)) given six times a week for two weeks followed by 12 weeks of thrice weekly dosing was more effective at producing sustained normal ALT values than either eight weeks of $10 \mathrm{MU}$ interferon six times a week or four weeks of $10 \mathrm{MU}$ six times a week followed by eight weeks of thrice weekly dosing. Multiple regression analysis of clinical parameters before treatment showed that the outcome was dependent upon treatment group $(p<0.001)$ and the initial hepatitis $C$ virus (HCV)-RNA value $(p<0.05)$. Anti-HCV titre and liver histology had a considerable but not significant effect on the response to treatment. The most frequently observed side effect was flu like syndrome, which
\end{abstract}

\section{Dosage}

$10 \times 10 \mathrm{MU}$ ( $\times 48$ times, total dosage of $480 \mathrm{MU})$

\section{Treatment period}

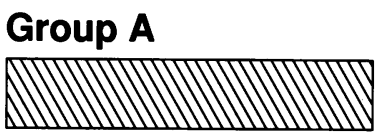

$$
8 \text { weeks Total } 8 \text { weeks }
$$

\section{Group B}

AMmom
4 weeks 8 weeks

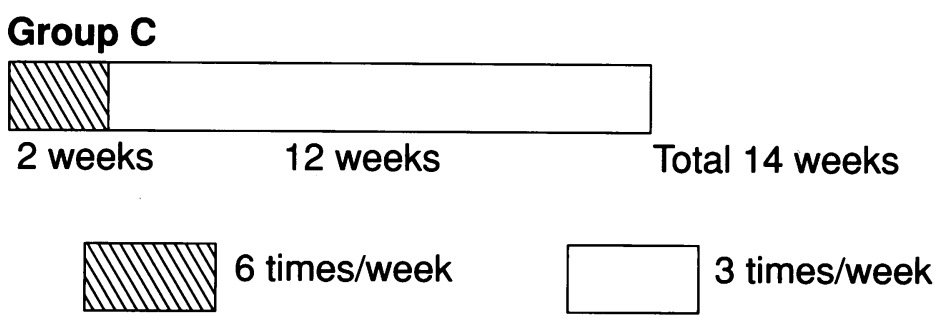

Figure 1 Study design. occurred in over $90 \%$ of patients. In addition, $21 \%$ of patients experienced some degree of hair loss. Treatment was stopped because of side effects in 11 of 126 $(9 \%)$ patients, evenly distributed between the three groups.

(Gut 1993; supplement: S114-S118)

Interferon was used in the treatment of non-A, non-B (NANB) hepatitis before the discovery of the hepatitis $\mathrm{C}$ virus (HCV) ${ }^{1}$ It is now widely recognised that interferon can reduce raised alanine aminotransferase (ALT) activities in patients with chronic hepatitis C, often to normal values. Improvement in liver histology is also observed. ${ }^{1}$ A second increase in ALT values is often seen after stopping interferon treatment. For this reason, long term treatment for six to 12 months has been attempted, but recurrence of hepatitis has still been observed in many patients. ${ }^{2}$ In addition, long term treatment has produced new problems such as the appearance of antiinterferon antibodies ${ }^{3}$ and induction of autoimmunity. ${ }^{4}$

Therefore, in order to reduce the rate of increases in ALT values after treatment, we have examined a variety of treatment regimens in chronic hepatitis C. We have obtained favourable results with high doses of interferon ${ }^{6}$ which are reported here.

\section{Methods}

A total of 126 patients presenting with liver histology consistent with chronic NANB hepatitis at 38 institutes entered into the study. None had a history of autoimmune liver disease, alcohol or drug induced liver disorder, chronic hepatitis B, or metabolic liver disease. The patients were assigned randomly to three treatment groups (Fig. 1). The total dose of interferon alfa-2b administered (480 million units (MU)) was the same in each group.

Serum biochemical tests, including ALT and aspartate aminotransferase (AST) activities and peripheral blood tests, were conducted every two weeks during treatment and every four weeks up to 12 months after stopping.

Anti-c100-3 antibody and second generation anti-HCV antibodies were assayed by the EIA method, ${ }^{78}$ and the presence of HCV-RNA was determined using nested polymerase chain reaction (PCR) with paired primers from the $5^{\prime}$ non-coding region according to the method of Okamoto et al..$^{9}$ In addition, quantitative and semiquantitative analyses were conducted for anti-c100-3 and HCV-RNA, respectively. 
TABLE I Patient characteristics before treatment

\begin{tabular}{|c|c|c|c|c|}
\hline \multirow[t]{2}{*}{ Characteristic } & \multicolumn{3}{|l|}{ Group } & \multirow[t]{2}{*}{ Statistical analysis } \\
\hline & $A$ & $B$ & $C$ & \\
\hline No of patients & 35 & 28 & 35 & \\
\hline Sex (men/women) & $26 / 9$ & $17 / 11$ & $30 / 5$ & $\mathrm{p}=0 \cdot 1413^{\star}$ \\
\hline Age (y) (mean (SEM)) & $47 \cdot 3(1 \cdot 8)$ & $46 \cdot 7(2 \cdot 4)$ & $44 \cdot 8(1 \cdot 9)$ & $p=0.6416 t$ \\
\hline \multicolumn{5}{|l|}{ Source of hepatitis: } \\
\hline Blood transfusion & 12 & 15 & 13 & $\mathrm{p}=0 \cdot 3975^{\star}$ \\
\hline Sporadic & 23 & 13 & 22 & \\
\hline \multicolumn{5}{|l|}{ Histological diagnosis: } \\
\hline $\mathrm{CPH}$ & 0 & 0 & 1 & \\
\hline $\mathrm{CAH} 2 \mathrm{~A}$ & 20 & 14 & 21 & $p=0.5256 \ddagger$ \\
\hline CAH2B & 15 & 14 & 13 & \\
\hline Histological activity index score (mean (SEM)) & $11 \cdot 1(0 \cdot 5)$ & $11.9(0.6)$ & $9 \cdot 8(0 \cdot 7)$ & $\mathrm{p}=0.0528 t$ \\
\hline Anti-c100-3 titre (mean (SEM)) & $75 \cdot 4(18 \cdot 5)$ & $94 \cdot 6(28 \cdot 8)$ & $98 \cdot 3(26 \cdot 8)$ & $\mathrm{p}=0.7711+$ \\
\hline \multicolumn{5}{|l|}{ HCV-RNA: } \\
\hline+ & 3 & 9 & 5 & $p=0.0465 \ddagger$ \\
\hline++ & 16 & 5 & 5 & $\mathrm{C}>\mathrm{A}$ \\
\hline+++ & 13 & 9 & 13 & $\mathrm{C}>\mathrm{B}$ \\
\hline++++ & 3 & 5 & 12 & \\
\hline Alanine aminotransferase (IU/l) (mean (SEM)) & $150 \cdot 6(19 \cdot 3)$ & $180 \cdot 8(31 \cdot 2)$ & $146 \cdot 6(17 \cdot 5)$ & $\mathrm{p}=0.523 t$ \\
\hline
\end{tabular}

${ }^{\star} \chi^{2}$ analysis, tanalysis of variance, $\ddagger$ Kruskal-Wallis analysis.

CPH: chronic persistent hepatitis; CAH: chronic active hepatitis.

\section{Results}

PATIENT DEMOGRAPHICS

Ninety eight of the $126(78 \%)$ patients enrolled in the study were evaluated; 35 from group A, 28 from group B, and 35 from group C. Of these, six were excluded from ALT analysis (two from each group) because they had normal ALT values. There was no significant difference between the three groups in characteristics before treatment (Table I). The following patients were not evaluated: patients negative for anti-c100-3 and second generation anti-HCV (group A four patients, group B three patients, and group $\mathrm{C}$ one patient), patients with cirrhosis (group A one patient, group B five patients, group C no patients) and, for other reasons (group A two patients, group B six patients, group C six patients). Analysis of patients excluded from the efficacy evaluation is shown in Table II.

\section{RETURN TO NORMAL OF ALT AFTER}

TREATMENT

Responders were defined as those patients whose ALT values returned to normal within

TABLE II Analysis of the patients excluded from the efficacy evaluation

\begin{tabular}{lrrr}
\hline & Group A & Group B & Group C \\
\hline No of patients enrolled & 42 & 42 & 42 \\
Anti-c100-3 (-ve), second generation anti-hepatitis C virus (-ve), & 4 & 3 & 1 \\
$\quad$ HCV-RNA (-ve) & 1 & 5 & 0 \\
Cirrhosis & 1 & 0 & 3 \\
Biopsy not done & 0 & 1 & 0 \\
Hepatitis B surface antigen (+ve) & 0 & 1 & 0 \\
Complications & 0 & 1 & 0 \\
Drop out & 1 & 3 & 3 \\
Stopped because of early appearance of side effects & 35 & 28 & 35 \\
No of patients evaluated & 2 & 2 & 2 \\
Alanine aminotransferase normal at initial treatment & & & \\
\hline
\end{tabular}

TABLE III Return to normal of alanine aminotransferase activities and response rates after interferon alfa- $2 b$ treatment

\begin{tabular}{lllll}
\hline Treatment group & \multicolumn{2}{l}{ ALT normal (\%) } & Response rate (\%) \\
\cline { 2 - 4 } & $\begin{array}{l}\text { End of } \\
\text { treatment }\end{array}$ & $\begin{array}{l}6 \text { months after } \\
\text { treatment }\end{array}$ & $\begin{array}{l}12 \text { months after } \\
\text { treatment }\end{array}$ & \\
\hline Group A (n=33) & $21 \cdot 2$ & $36 \cdot 4$ & $31 \cdot 3$ & $21 \cdot 2$ \\
Group B $(\mathrm{n}=26)$ & $42 \cdot 3$ & $42 \cdot 3$ & $43 \cdot 5$ & $42 \cdot 3$ \\
Group C $(\mathrm{n}=33)$ & $51 \cdot 5$ & $60 \cdot 6$ & $56 \cdot 3$ & $54 \cdot 5^{\star}$ \\
\hline
\end{tabular}

${ }^{\star} \mathrm{p}<0.05$, statistically different to response rate in group $\mathrm{A}$. six months of completion of interferon treatment and remained normal for at least six months. ${ }^{1}$ Patients with abnormal values at either time point were defined as nonresponders. ${ }^{10}$

Table III shows the rate at which ALT values returned to normal for each group at the end of treatment and at six months and 12 months after treatment, together with overall response rates. Both a return to normal ALT values and response rate at each time point were highest in group $\mathrm{C}$, followed in descending order by group B and group A. A response rate of over $50 \%$ was achieved with group $\mathrm{C}$, which was statistically significantly different to that obtained in group A $(p<0.05)$.

\section{CHANGES IN ANTI-C100-3}

The mean anti-c100-3 titre declined during treatment in all three groups. At six months after treatment it had risen above that seen at the end of treatment in groups $\mathbf{A}$ and $\mathbf{B}$, whereas in group $\mathrm{C}$ a further decline was observed (Fig 2). At six months after treatment, five patients out of 26 in group A, 11 out of 26 in group B, and 12 out of 31 in group $C$ had more than a $75 \%$ reduction in anti-c100-3. Of these patients, two of 26 in group A, four of 26 in group B, and two of 31 in group $\mathrm{C}$ were negative for anti-c100-3.

\section{HCV-RNA NEGATIVITY DURING AND AFTER} TREATMENT

Table IV shows the HCV-RNA negativity rates for groups A, B, and C at two weeks after the start of treatment, at the end of treatment, and 24 weeks after treatment.

The HCV-RNA negativity rate at the end of two weeks' treatment, a time point at which treatment regimens were the same for all groups, was lower in group A compared with groups $\mathbf{B}$ and $\mathrm{C}$. Higher negativity rates were seen with the longer duration of daily dosing (that is six times per week for eight weeks) at the end of interferon treatment, with almost 95\% HCV-RNA negativity achieved in group A. This trend was reversed, however, when rates at six months after treatment were 


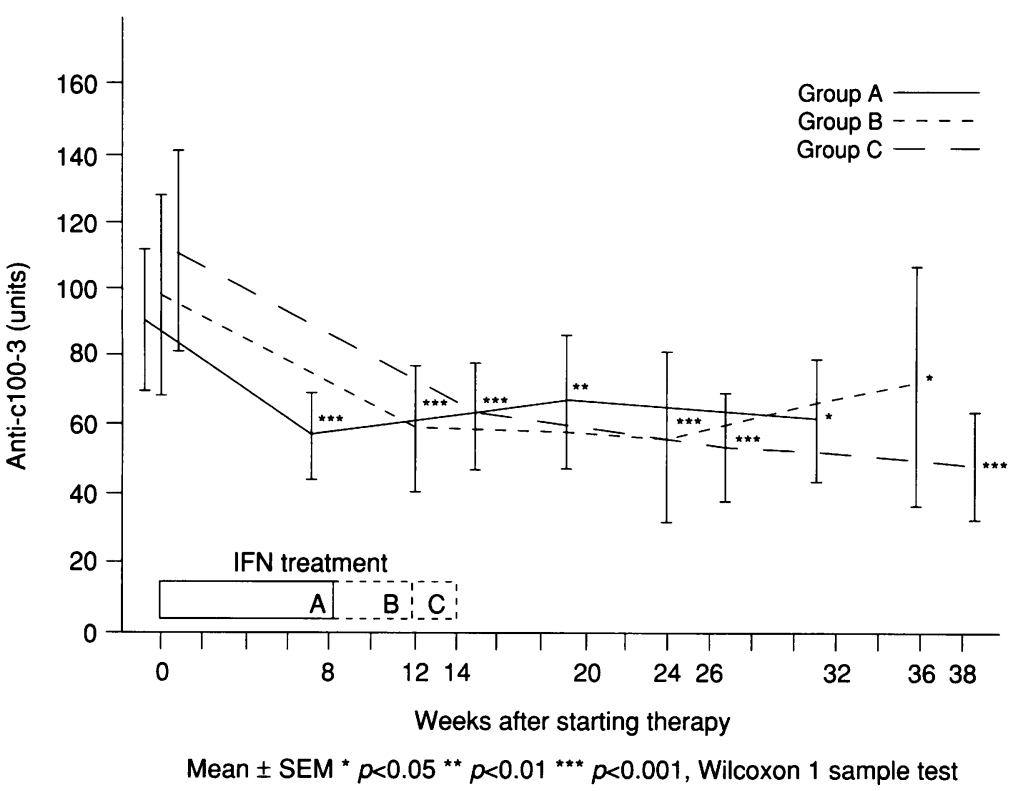

Figure 2 Changes in anti-c100-3 titre.

TABLE IV Hepatitis $C$ virus-RNA negativity rates (\%) during and after interferon treatment ${ }^{*}$

\begin{tabular}{|c|c|c|c|}
\hline & \multirow{2}{*}{$\begin{array}{l}\text { During treatment } \\
(+2 \text { weeks) } \\
\text { No (\%) }\end{array}$} & \multicolumn{2}{|l|}{ After treatment } \\
\hline & & $\begin{array}{l}\text { End of treatment } \\
\text { No (\%) }\end{array}$ & $\begin{array}{l}24 \text { weeks after treatment } \\
\text { No }(\%)\end{array}$ \\
\hline $\begin{array}{l}\text { Group A } \\
\text { Group B } \\
\text { Group C } \\
\text { Total }\end{array}$ & $\begin{array}{l}18 / 26(69 \cdot 2) \\
15 / 19(78 \cdot 9) \\
22 / 28(78 \cdot 6) \\
55 / 73(75 \cdot 3)\end{array}$ & $\begin{array}{l}32 / 34(94 \cdot 1) \\
23 / 28(82 \cdot 1) \\
23 / 35(65 \cdot 7) \\
78 / 97(80 \cdot 4)\end{array}$ & $\begin{array}{r}8 / 28(28 \cdot 6) \\
9 / 22(40 \cdot 9) \\
14 / 29(48 \cdot 3) \\
31 / 79(39 \cdot 2)\end{array}$ \\
\hline
\end{tabular}

^Plasma samples could not be obtained for all patients at all time points.

TABLE V Response to treatment according to patient demographic data beforehand

\begin{tabular}{ccccc}
\hline \multicolumn{5}{c}{ No (\%) of responders } \\
\cline { 2 - 5 } & $\begin{array}{l}\text { Group } A \\
(n=33)\end{array}$ & $\begin{array}{l}\text { Group } B \\
(n=26)\end{array}$ & $\begin{array}{l}\text { Group } C \\
(n=33)\end{array}$ & Total \\
\hline $\begin{array}{l}\text { Liver histology: } \\
\text { CAH2A }\end{array}$ & $6 / 18$ & $5 / 13$ & $13 / 20$ & $24 / 51$ \\
CAH2B & $(33)$ & $(38)$ & $(65)$ & $(47)$ \\
HCV-RNA & $1 / 15$ & $6 / 13$ & $5 / 13$ & $12 / 41$ \\
+ & $(7)$ & $(46)$ & $(38)$ & $(29)$ \\
++-+++ & $(67)$ & $(50)$ & $(100)$ & $(67)^{\star}$ \\
& $5 / 30$ & $7 / 18$ & $14 / 29$ & $26 / 77$ \\
Anti-c100-3 & $(17)$ & $(39)$ & $(48)$ & $(34)^{\star}$ \\
Titre 0-10 & $4 / 14$ & $5 / 7$ & $6 / 10$ & $15 / 31$ \\
$10-720$ & $(29)$ & $(71)$ & $(60)$ & $(48)$ \\
& $3 / 19$ & $6 / 19$ & $12 / 23$ & $21 / 61$ \\
& $(16)$ & $(32)$ & $(52)$ & $(34)$ \\
\hline
\end{tabular}

${ }^{\star} \mathrm{p}<0.05$, significant difference between groups, $\left(\chi^{2}\right.$ test $)$. CAH2A: chronic active hepatitis type $2 \mathrm{~A}$ (moderate). CAH2B: chronic active hepatitis type $2 \mathrm{~B}$ (severe).

TABLE VI Treatment-related adverse experiences (all patients)

\begin{tabular}{|c|c|c|c|c|c|}
\hline & \multicolumn{5}{|c|}{ No (\%) of patients } \\
\hline & $\begin{array}{l}\text { Group } A \\
(n=42)\end{array}$ & $\begin{array}{l}\text { Group } B \\
(n=42)\end{array}$ & $\begin{array}{l}\text { Group } C \\
(n=42)\end{array}$ & $\begin{array}{l}\text { Overall } \\
(n=126)\end{array}$ & $\chi^{2}$ test \\
\hline $\begin{array}{l}\text { All patients with any } \\
\text { adverse experiences }\end{array}$ & $40(95 \cdot 2)$ & $41(97 \cdot 6)$ & $41(97 \cdot 6)$ & $122(96 \cdot 8)$ & $\mathrm{p}=0.9682$ \\
\hline $\begin{array}{l}\text { Flu-like symptoms } \\
\text { Hair loss } \\
\text { Depression }\end{array}$ & $\begin{array}{c}39(92 \cdot 9) \\
5(11 \cdot 9) \\
3(7 \cdot 1)\end{array}$ & $\begin{array}{l}41(97 \cdot 6) \\
9(21 \cdot 4) \\
0\end{array}$ & $\begin{array}{c}41(97 \cdot 6) \\
12(28 \cdot 6) \\
2(4 \cdot 8)\end{array}$ & $\begin{array}{c}121(96 \cdot 0) \\
26(20 \cdot 6) \\
5(4 \cdot 0)\end{array}$ & $\begin{array}{l}p=0.7911 \\
p=0.2686 \\
p=0.5216\end{array}$ \\
\hline
\end{tabular}

Others (<5.0\%): chest pain, insomnia, abdominal pain, weight loss, menstrual disorder, stomatitis, gingival bleeding, blocked ear, hyperthyroidism, abnormal thinking, anxiety, taste abnormality, arrhythmia, stomach discomfort, nervousness, coldness of lower extremities, dizziness. compared. Higher HCV-RNA negativity rates were obtained with group $\mathrm{C}$; that is, after the longest treatment period (14 weeks).

ANALYSIS OF PRETREATMENT FACTORS

AFFECTING RESPONSE RATE

Multiple regression analysis of pretreatment factors affecting the response rate indicated a significant effect of treatment schedule $(\mathrm{p}<0.001)$ and semiquantitatively determined HCV-RNA values $(p<0 \cdot 05)$. Liver histology and anti-c100-3 titre were also shown to have an effect on the response to treatment, although this effect was not significant. Results for liver histology, HCV-RNA, and antic100-3 titre are given in Table V. No significant difference in response dependent upon age, sex, source of hepatitis, or ALT values was noted.

ADVERSE EXPERIENCES WITH TREATMENT Adverse events observed during and after interferon treatment are given in Table VI. No significant difference in the incidence of side effects was noted between the three treatment groups; flu like syndrome was experienced by almost all patients. Hair loss was seen in $20.6 \%$ of patients, and was observed from the latter half of the treatment period until after the end of treatment, suggesting a connection with the duration of treatment. All patients recovered within six months. Depression was experienced by three patients in group $A$ and two patients in group C. In group B, hyperthyroidism and arrhythmia were seen in one patient each.

It was necessary to stop treatment because of side effects in 11 out of 126 patients (9\%): three patients in group $A$, four patients in group $B$, and four patients in group $C$. The reasons were depression in three patients, general malaise in four patients, granulocytopenia in two patients, and anorexia and fever in two patients. No dose reductions were necessary, except in one patient whose dosage was first reduced to $5 \mathrm{MU}$ and then treatment was stopped.

Early stage onset of adverse events was observed in seven patients, and these seven, although they were included in the evaluation of adverse experiences, were not included in the efficacy evaluation. The remaining four patients were included in the efficacy evaluation; three were responders (one patient in group $A$, two in group $C$ ) and one was a non-responder (in group A).

Anti-interferon antibodies on bioassay (cytopathic effect assay) were observed in three patients, all of whom were responders. In one patient, anti-interferon antibodies more than 144-times dilution were detected even before treatment. No flu like symptoms (fatigue, fever, headache, myalgia) nor any change in ALT values were observed in this patient.

\section{Discussion}

The efficacy of interferon in the treatment of chronic hepatitis $\mathrm{C}$ was first reported by 


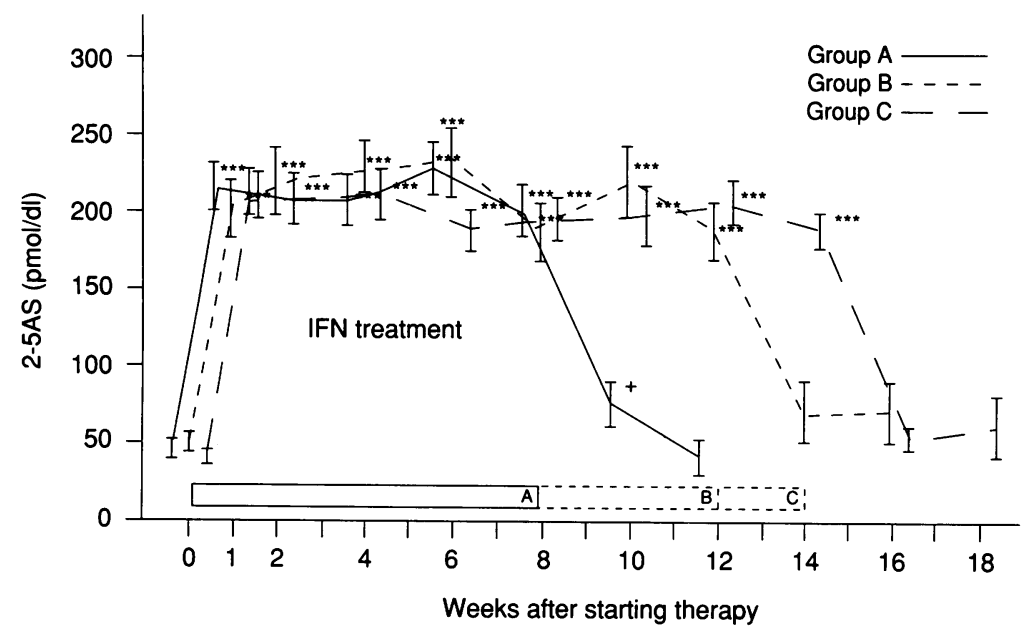

Mean \pm SEM $+p<0.1^{*} p<0.05^{\star *} p<0.01^{* \star *} p<0.001$, Wilcoxon 1 sample test

Figure 3 Changes in the 2', 5'oligoadenylate synthetase activity.

Hoofnagle et al in $1986 .{ }^{1}$ Since then, there have been many reports and, in most cases, the treatment regimen has been 3 to $6 \mathrm{MU}$ three times weekly for four to 12 months. ${ }^{2} 1112$ In all cases, ALT activities were reduced during treatment but relapse occurred in about $50 \%$ of patients after stopping therapy.

We conducted a dose comparison study of interferon beta, administered daily for eight weeks, and examined the relation between interferon dosage and the return to normal of ALT activities after stopping treatment. ${ }^{13} \mathrm{~A}$ second increase in ALT was observed in all cases when daily dosage was low (1 MU), while a high rate of sustained normal values was obtained when the daily dosage was high (6 MU). The relation between daily dosage and sustained normal ALT values was also examined with interferon alfa-2b, and it was found that the higher the daily dosage and the longer the duration of treatment, the higher the rate of sustained normal ALT values. ${ }^{14}$ Based on these results, we selected a daily dose of 10 MU and examined the relation between treatment schedule and sustained normal ALT values.

As shown in Tables III and IV, 10 MU daily for two weeks followed by 12 weeks of thrice weekly treatment (group C) resulted in a high rate of normal ALT values, response rate, and HCV-RNA negativity rate, all of which were superior to those obtained with either eight weeks of daily treatment (group A) or four weeks of daily treatment followed by eight weeks of thrice weekly treatment (group B).

The first reason for this difference in effect, despite an identical total administered dose in all three groups, is the change in the serum concentration of interferon alfa. When it is administered intramuscularly in a single dose, it can still be detected in serum after 24 hours, ${ }^{15}$ which suggests that it may accumulate on repeated dosing. When interferon is administered daily, both $T_{\max }$ and $\mathrm{AUC}_{0 \rightarrow \infty}$ become increasingly higher at day 1 , day 7 , and day 28, showing accumulation. However, both $T_{\max }$ and $\mathrm{AUC}_{0-\rightarrow \infty}$ are reduced by day 56 , suggesting accelerated degradation of interferon. ${ }^{15}$ For this reason, interferon was utilised more effectively in group B than in group $A$ and an even better response rate was seen with group $C$.

Another explanation for the different response rates relates to the serum 2'5'-oligoadenylate synthetase (2-5AS) activity. 2-5AS activity (measured by Eiken's RIA kit) was induced by interferon, reaching peak values after one week of treatment in all groups; levels were sustained thereafter for the duration of treatment. Changing the dose frequency from six times to three times per week did not result in a significant reduction in 2-5AS activity in either group B or C (Fig 3).

The HCV-RNA negativity rate at the end of treatment, as determined by PCR, however, was highest in group $\mathrm{A}$ and lowest in group $\mathrm{C}$. Therefore, a longer duration of daily treatment resulted in stronger suppression of $\mathrm{HCV}$ proliferation. The short duration of treatment (eight weeks) may account for the high rate of reappearance of HCV-RNA and the reoccurrence of high ALT values.

The HCV-RNA titre was shown to be a pretreatment factor affecting the response rate. If a simple method of detecting HCV-RNA before interferon treatment were available, it might be possible to select the optimal daily dosage and duration of treatment for each patient. Liver histology would also be included as a factor.

An increase in flu like syndrome occurred with the high dose of $10 \mathrm{MU}$ daily compared with $3 \mathrm{MU}$ and $6 \mathrm{MU}$, but symptoms were adequately controlled by antipyretics. Decreases in leukocyte and platelet counts were also slightly more frequent with higher doses, but did not usually necessitate ending treatment. Treatment was stopped in only one patient because of leukocytopenia. There were no cases of bacterial infection during treatment. Studies have indicated that the changes in the leukocyte count during interferon treatment are not the result of bone marrow suppression but a change in the distribution of leukocytes in the body. ${ }^{16}$

The problem of interferon treatment induced autoimmunity has recently come to light. In this study, neither the appearance of autoantibody nor induction of autoimmunity was observed, perhaps because the longest duration of treatment was 14 weeks. One case of hyperthyroidism was seen, however, in a patient who was negative for all thyroid related autoantibodies.

\section{Conclusion}

The results show that treatment of chronic hepatitis $\mathrm{C}$ with high doses of interferon is effective biochemically as well as virologically. A sustained return to normal of the ALT activity after stopping treatment was achieved in more than $50 \%$ of patients. The best treatment regimen among those studied was two weeks of daily dosing followed by 12 weeks of dosing three times a week. No new side effects were detected with $10 \mathrm{MU}$ daily, and al side effects which occurred were manageable. 
1 Hoofnagle $\mathrm{JH}$, Mullen $\mathrm{KD}$, Jones $\mathrm{DB}$, et al. Treatment of chronic non-A, non-B hepatitis with recombinant human chronic non-A, non-B hepatitis with recombinant hun
alpha-interferon. $N$ Engl $₹$ Med 1986; 315: 1575-8.

2 Tine F, Magrin S, Craxi A, Pagliaro L. Interferon for non-A, non-B chronic hepatitis. I Hepatol 1991; 13: 192-9.

3 Von Wussow P, Freund M, Block B, Diedrich H, Poliwoda $\mathrm{H}$ Deicher H. Clinical significance of anti-IFN- $\alpha$ antibody titres during interferon therapy. Lancet 1987; ii: 635-66.

4 Burman P, Totterman TH, Oberg K, Karlsson FA. Thyroid autoimmunity in patients on long-term therapy with leukocyte-derived interferon. 7 Clin Endocrinol Metab 1986; 63: 1086-90.

5 Silva MO, Reddy KR, Jeffers LJ, Hill M, Schiff ER Interferon-induced chronic active hepatitis? Gastroenterology 1991; 101: 840-2.

6 Iino $\mathrm{S}$. Treatment of chronic hepatitis $\mathrm{C}$ with high-dose interferon $\alpha-2 b-a$ multicenter study. Dig Dis Sci 1993 (in press)

Kuo G, Choo QL, Alter HJ, et al. An assay for circulating antibodies to a major etiologic virus of human non-A non-B hepatitis. Science 1989; 244: 362-4.

8 van der Poel CL, Cuypers HTM, Reesink HW, et al. Confirmation of hepatitis $C$ virus infection by new fourantigen recombinant immunoblot assay. Lancet 1991; 337: $317-9$

9 Okamoto $\mathrm{H}$, Okada $S$, Sugiyama $\mathrm{Y}$, et al. Detection of hepatitis $C$ virus RNA by a two-stage polymerase chain reaction with two pairs of primers deduced from the 5'-noncoding region. fap 7 Exp Med 1990; 60: 215-22.

10 Iino S. Annual report from intractable hepatitis research group. Tokyo; Ministry of Health and Welfare, 1989: 163 (in Japanese):

11 Di Bisceglie AM, Martin P, Kassianides C, et al. Recombinant interferon alfa therapy for chronic hepatitis C: A randomized, double-blind, placebo-controlled trial. $N$ Engl f Med 1989; 321: 1506-10.

12 Marcellin P, Boyer N, Giostra E, et al. Recombinant human $\alpha$-interferon in patients with chronic non- $A$, non- $B$ hepatitis: a multicenter randomized controlled trial from France. Hepatology 1991; 13: 393-7.

13 Fujioka $S$, Hino K, Yasuda $S$, et al. Interferon treatment in chronic non-A, non-B hepatitis. In: Shikata $T$, Purcell
$\mathrm{RH}$, Uchida T, eds. Viral hepatitis $C, D$ and $E$. RH, Uchida T, eds. Viral hepatitis $C, D$ and $E$. Amsterdam, New York, Oxf

14 Hino $\mathrm{K}$, Suzuki $\mathrm{H}$, Yamamoto $\mathrm{S}$, et al. A comparative study of interferon $\alpha-2 b$ for the treatment of chronic hepatitis C (in Japanese). The Clinical Report 1992; 26: 409-42. 15 Hino K, Nashida Y, Kondo T, et al. Clinical pharmacology $839-51$

16 Hino K, Kondo T, Kaku K, et al. Biologic effects of IFN in patients with chronic hepatitis B. In: Sung J-L, Hong Kong: Excerpta Medica, 1990: 345-54. 